EVS28

KINTEX, Korea, May 3-6, 2015

\title{
Analysis of regenerative braking effect to improve fuel economy for E-REV bus based on simulation
}

\author{
Jongdai Choi ${ }^{1}$, Jongryeol Jeong ${ }^{1}$, Yeong-il Park ${ }^{2}$, Suk Won Cha ${ }^{1}$ \\ ${ }^{I}$ School of Mechanical \& Aerospace Engineering, Seoul National University, Gwanak-ro 1, Gwanak-gu Seoul 151-744, \\ Republic of Korea \\ ${ }^{2}$ Department of Mechanical System Design Engineering, Seoul National University of Science and Technology, \\ Gongreung-ro 232, Nowon-gu, Seoul 139-743, Republic of Korea
}

\begin{abstract}
Emission regulations are strict globally and oil price goes up continuously. There are many researches for eco-friendly vehicle to solve these problems. Among them, extended-range electric vehicle (E-REV) utilizes electric energy directly and can drive extended range by generating additional energy. It has characteristics of both an electric vehicle (EV) and hybrid electric vehicle (HEV). According to state of charge (SOC) for battery, E-REV can drive either EV mode or HEV mode. In this study, effect of regenerative braking is analysed to improve fuel economy for the E-REV bus when vehicle drives as EV mode. In advance, sizing of components is conducted to develop forward simulator for calculating fuel economy. The forward simulator is developed using Matlab/Simulink. Considering performance for battery, limited regenerative braking is applied in the forward simulator and the effect of regenerative braking is analysed when driving cycles are determined. And then effect of coast driving is analysed by comparing to constant speed driving. Effect of regenerative braking when vehicle is coasting is verified and this result can be utilized to develop control logic for regenerative braking in further research.
\end{abstract}

Keywords: Extended-Range Electric Vehicle, Regenerative braking, Coast driving, Fuel economy

\section{Introduction}

Demands for eco-friendly vehicle such as EV and HEV are increasing. Many companies have developed various types for vehicle based on electricity. Among these systems, the extendedrange electric vehicle (E-REV) is an electric vehicle concept that has a light engine to allow an extended driving range. It has characteristics of both an electric vehicle (EV) and hybrid electric vehicle (HEV).[1] One of the most important features of these vehicles based electricity is their ability to recover significant amounts of braking energy. Recovering the braking energy and reusing it can significantly improve the fuel economy of the vehicle which is subject to frequent braking events such as a city bus.[2] There also are eco-driving and economical speed to enhance the fuel economy for vehicle. As an eco-driving, the coast driving is considered for the E-REV bus. The basic idea of coast driving it to put more kinetic energy in vehicle during acceleration and uses that stored energy without additional energy source during coasting.[3] In this study, effect of regenerative braking is analysed when the E-REV bus is coasting. Forward simulator for calculating fuel economy is developed and the constrained regenerative braking torque maps are applied to guarantee performance of battery. Based on this forward 
simulator, results of fuel economy are obtained and analysed to verify advantages for E-REV bus.

\section{Target vehicle system}

\subsection{Extended-range electric vehicle}

Target vehicle system is an extended-range electric vehicle bus. It is similar to series plug-in hybrid electric vehicle. It has two driving motors, battery, engine and generator. In this study, engine and generator for additional generation are abbreviated to genset. Figure 1 shows configuration of E-REV.

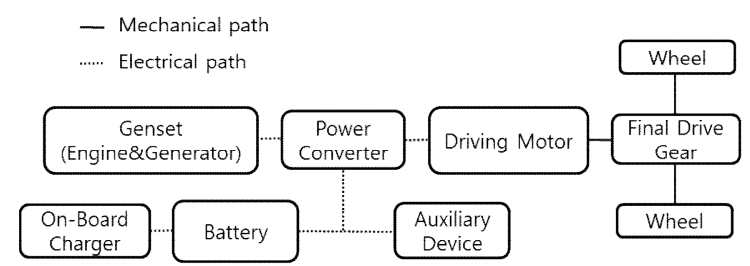

Figure 1: Configuration of Vehicle System

\subsection{Sizing of components}

Size of each component is determined according to the target vehicle performance using some equations.[4],[5] The capacity of the driving motor is selected by maximum speed $(100 \mathrm{~km} / \mathrm{h})$, gradeability $(20 \%$ at $20 \mathrm{~km} / \mathrm{h})$ and acceleration ( $80 \mathrm{~km} / \mathrm{h}$ during 40 seconds). Also, driving cycle circulating Busan in Republic of Korea is considered. Table 1 is vehicle specification and Figure 2 shows information of driving cycle for Busan city. The capacity of the battery is determined by the all electric range (AER). The AER for the target bus is $30 \mathrm{~km}$. The capacity of genset is determined by the amount of additional power required to sustain a state of charge (SOC) of the battery when the vehicle drives according to its set driving cycles. Table 2 is result of components sizing.

Table 1: Vehicle specification

\begin{tabular}{|c|c|c|}
\hline & Unit & Value \\
\hline Air Density & $\mathrm{Kg} / \mathrm{m}^{3}$ & 1.293 \\
\hline Frontal Area & $\mathrm{m}^{2}$ & 6.6 \\
\hline Air Drag & & 0.8 \\
\hline Rolling Resistance & & 0.01 \\
\hline Tire Radius & $\mathrm{m}$ & 0.478 \\
\hline Gravity & $\mathrm{m} / \mathrm{s}^{2}$ & 9.81 \\
\hline Final Drive Gear Effi. & $\%$ & 95 \\
\hline Vehicle Mass (CVW) & $\mathrm{kg}$ & 12000 \\
\hline Auxiliary Power Loss & $\mathrm{W}$ & 3500 \\
\hline
\end{tabular}
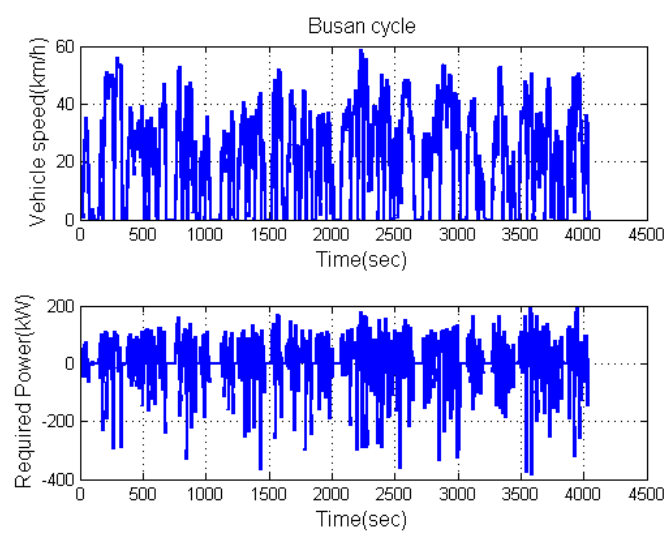

Figure 2: Driving cycle for Busan city

Table 2: Result of components sizing

\begin{tabular}{|c|c|}
\hline & Capacity \\
\hline Genset $(\mathrm{kW})$ & 120 \\
\hline Driving Motor $(\mathrm{kW})$ & $240(120$ of each) \\
\hline Battery $(\mathrm{Ah})$ & 120 \\
\hline
\end{tabular}

\section{Forward simulator with limited regenerative braking}

Using results of components sizing, forward simulator for calculating fuel economy is developed. Autonomie based on Matlab/Simulink is utilized for developing simulator. Figure 3 shows forward simulator based on Autonomie.[6] According to performance of battery, regenerative braking is limited by applying constrained torque maps. They consider vehicle speed, brake signal and voltage of battery.

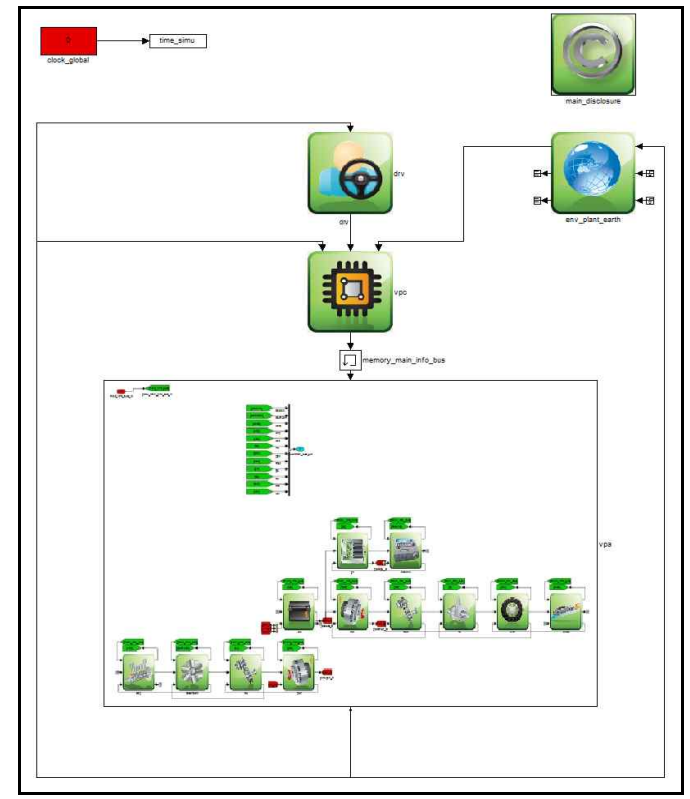

Figure 3: Forward simulator 


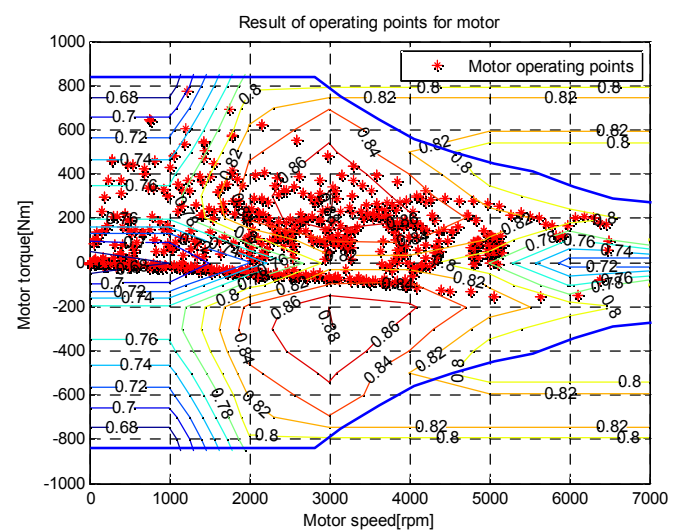

Figure 4: Result of operating points for driving motor

Figure 4 shows operating points for driving motor when the constrained torque maps are applied. Fuel economy for simulation applied regenerative braking torque maps is compared to that of simulation without regenerative braking. The fuel economy increases up to $11.3 \%$ contingent upon regenerative braking.

\section{Analysis of coast driving}

\subsection{Coast driving compared to constant driving}

To enhance fuel economy further, eco-driving and economical speed can be considered. As an eco-driving, the coast driving is considered for $\mathrm{E}$ REV bus in this research. The basic idea of coast driving it to put more kinetic energy in vehicle during acceleration and uses that stored energy without additional energy source during coasting. To verify effect of the coast driving for E-REV bus, its fuel economy is compared to that of constant driving. During acceleration, all cases consume same energy to propel. For the constant driving, vehicle speed increases up to target speed and keeps constant speed. On the other hand, for the coast driving, vehicle accelerates up to more speed than target speed and drives using vehicle inertia. To verify effect of coast driving purely, coast driving excludes regenerative braking. Figure 5 shows comparison between constant driving and coast driving as EV mode. Because equivalent energy is consumed to accelerate, each consumed energy is compared from black square to same accumulated distance. Table 3 is result of consumed energy and fuel economy for constant driving and coast driving. Compared to the constant driving, the coast driving has increase of $39.7 \%$ in terms of fuel economy. According to vehicle mass and vehicle speed, effect of coast driving for E-REC bus is verified.
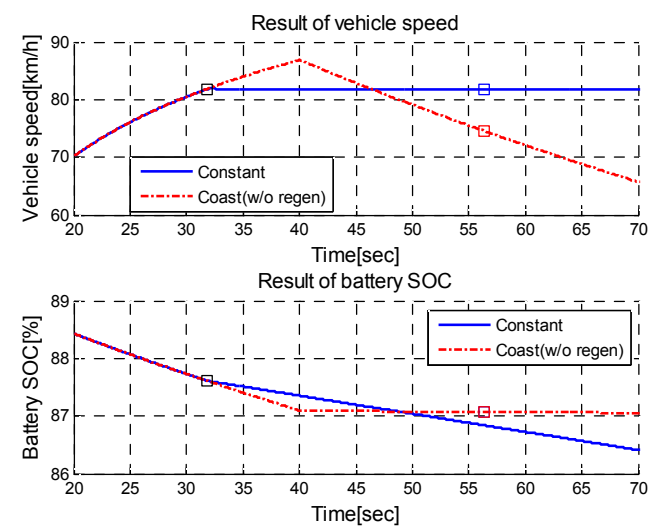

Figure 5: Comparison between constant driving and coast driving as EV mode

Table 3: Result of consumed energy and fuel economy for constant driving and coast driving

\begin{tabular}{|c|c|c|}
\hline & $\begin{array}{c}\text { Consumed } \\
\text { Energy }(\mathrm{kJ})\end{array}$ & $\begin{array}{c}\text { Fuel Economy } \\
(\mathrm{km} / \mathrm{kWh})\end{array}$ \\
\hline Constant & 2317.3 & 0.868 \\
\hline Coast & 1659.5 & 1.213 \\
\hline
\end{tabular}

\subsection{Coast driving with regenerative braking}

After comparison between constant driving and coast driving, effect of regenerative braking is analysed when vehicle is coasting. As mentioned, simulation consists of equal condition. Whether regenerative braking or not is just different when vehicle drives as coast driving. To compare consumed energy, same distance is considered. Because of additional braking except for resistance, the coast driving with regenerative braking takes more time to reach same distance. Figure 6 shows comparison between the coast driving without regenerative braking and the coast driving with regenerative braking. Table 4 is result of consumed energy and fuel economy for coast driving with regenerative braking. Compared to the coast driving without regenerative braking, the coast driving with regenerative braking has increase of $3.5 \%$ in terms of fuel economy. When vehicle drives as coast driving, difference of fuel economy is analysed contingent upon regenerative braking. Compared to constant driving, the coast driving with regenerative braking has increase of $44.5 \%$. This advantage is verified. And then it also is useful to develop control logic of regenerative braking. 

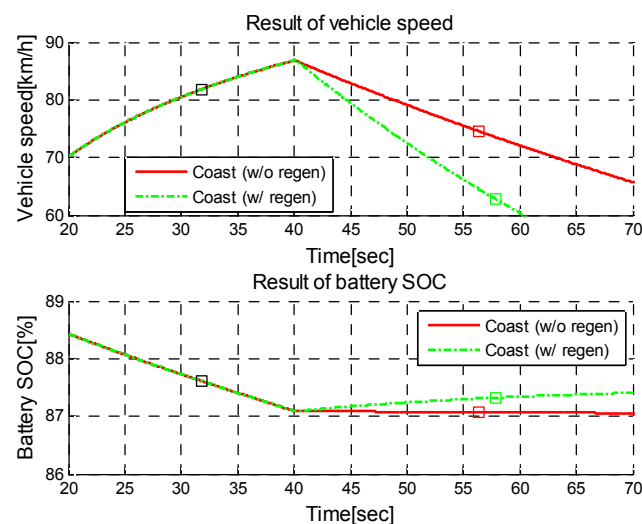

Figure 6: Coast driving with regenerative braking

Table 4: Result of consumed energy and fuel economy for coast driving with regenerative braking

\begin{tabular}{|c|c|c|}
\hline & $\begin{array}{c}\text { Consumed } \\
\text { Energy }(\mathrm{kJ})\end{array}$ & $\begin{array}{c}\text { Fuel Economy } \\
(\mathrm{km} / \mathrm{kWh})\end{array}$ \\
\hline w/o regen & 1659.5 & 1.213 \\
\hline w/ regen & 1606.0 & 1.255 \\
\hline
\end{tabular}

\section{Conclusion}

Forward simulator for calculating fuel economy is developed and constrained regenerative torque maps are applied considering performance of battery. To verify effect of coast driving, fuel economy for coast driving without regenerative braking is compared to that of constant driving. The coast driving has increase of $39.7 \%$ in terms of fuel economy. Also, additional simulation is conducted to verify effect of coast driving with regenerative braking. Compared to coast driving without regenerative braking, coast driving with regenerative braking has increase of $3.5 \%$ in terms of fuel economy. Effect of coast driving with regenerative braking is verified and this advantage can be utilized to develop control logic of regenerative braking in further research.

\section{Acknowledgments}

This work was supported by the Industrial Strategic Technology Development Program (10033126) under the Ministry of Knowledge Economy, Republic of Korea and the National Research Foundation of Korea (NRF) grant funded by the Ministry of Science, ICT \& Future Planning (MSIP) (No. 2009-0083495)

\section{References}

[1] D. Shin, B. Lee, Global Market Forecasts and Technology Issues of Plug-in HEV, Auto Journal of KSAE, 10(2011), 20-25.
[2] Y. Gao, L. Chen, M. Ehsani, Investigation of the Effectiveness of Regenerative Braking for EV and $H E V, \quad$ ISSN 0148-7191, 1999-01-2910, SAE International, 1999.

[3] J. Lee, D.J. Nelson, Vehicle Inertia Impact on Fuel Consumption of Conventional and Hybrid Electric Vehicles Using Acceleration and Coast Driving Strategy, ISSN 0148-7191，2009-01-1322， SAE International, 2009.

[4] D. Lee, J. Jeong, Y. Park, S. W. Cha, The Component Sizing Process and Performance Analysis of Extended-Range Electric Vehicles (E-REV) Considering Required Vehicle Performance, Transactions of KSAE, ISSN 1225-6382, 21(2013), 136-145.

[5] D. H. Lee, N. W. Kim, J. R. Jeong, Y. I. Park, S. W. Cha, Component Sizing and Engine Optimal Operation Line Analysis for a Plug-In Hybrid Electric Transit Bus, International Journal of Automotive Technology, ISSN 1229-9138, 14(2013), 459-469.

[6] J. Kim, C. Lee, Y. Park, Analysis of Fuel Economy for Series Plug-in Hybrid Electric Bus according to Engine Operation Strategy Based on Simulation, ISSN 1225-6382, 22(2014), 102-107.

\section{Authors}

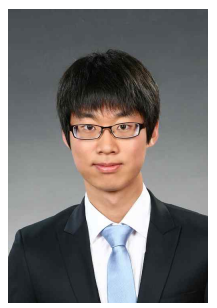

Jongdai Choi received B.S. degree in Mechanical Design and Automation Engineering from Seoul National University of Science and Technology, Republic of Korea, in 2011. He is currently a Ph.D candidate in Mechanical and Aerospace Engineering from Seoul National University, Republic of Korea. His research interests are modelling, simulation and control strategy of hybrid electric vehicles.

Jongryeol Jeong received B.S.

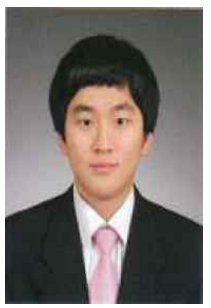
degree in Mechanical Engineering from Korea University, Republic of Korea, in 2009 . He is currently a Ph. $D$ candidate in Mechanical and Aerospace Engineering from Seoul National University, Republic of Korea. His research interests are modelling, simulation and control strategy of hybrid electric vehicles. 
Yeong-il Park received MS and $\mathrm{Ph}$. $\mathrm{D}$ in Department of Mechanical Engineering from Seoul National University in 1981 and 1991 respectively. $\mathrm{He}$ is currently a Professor in School of Mechanical Design and Automation Engineering, Seoul National University of Science and Technology. His research interests are dynamic system of vehicle, hybrid vehicle control system and driveline system.

Suk Won Cha received bachelor's degree in Department of Naval Architecture and Ocean Engineering from Seoul National University, South Korea, in 1994. The M.S. and the Ph.D. degree in Department of Mechanical Engineering from Stanford University, in 1999 and 2004, respectively. He is currently an Associate Professor in School of Mechanical and Aerospace Engineering, Seoul National University. His research interests are fuel cell systems, design of hybrid vehicle systems and application of nanotechnology to energy conversion devices. 